\title{
Peptide mimicry of carbohydrate epitopes on human immunodeficiency virus
}

\author{
Michael Agadjanyan, Ping Luo, M.A. Julie Westerink', Lisa A. Carey, Wendy Hutchins', \\ Zenon Steplewski², David B. Weiner, and Thomas Kieber-Emmons*
}

Department of Pathology and Laboratory Medicine, University of Pennsylvania, 36th and Hamilton Walk, Philadelphia, PA 19104-6082. ${ }^{1}$ Department of Medicine, Medical College of Ohio, Toledo, OH. ${ }^{2}$ Department of Medicine, Thomas Jefferson University, Philadelphia, PA. *Corresponding auther (e-mail: tom@xray.med.upenn.edu).

Received 16 December 1996; accepted 20 March 1997

\begin{abstract}
Cancer-related, mucin-type carbohydrate epitopes, principally mannose and sialo-syl residues, are expressed on the envelope protein gp160 of the human immunodeficiency virus (HIV). Anticarbohydrate antibodies directed toward these and other carbohydrate epitopes are known to neutralize HIV-1 infection by cell-free virus. Carbohydrates, however, being $T$ cell-independent antigens, typically elicit diminished immune responses. To overcome this potential draw back, we have examined the ability of peptides that mimic such epitopes to elicit immune responses that cross-react with carbohydrate structures. We report that mouse polyclonal antisera generated against peptides that mimic mucin-related carbohydrate epitopes have anti-HIV-1 activity. Generation of antibodies was not Ir-gene restricted, as at least two different strains of mice, Balb/c $\left(\mathrm{H}-2^{\mathrm{d}}\right)$ and $\mathrm{C} 57 \mathrm{Bl} / 6\left(\mathrm{H}-2^{b}\right)$, responded equally to the peptides. The antipeptide sera displayed neutralizing activity against HIV-I/MN and HIV-I/3B viral strains. This neutralization was as good as human anti-HIV sera. These results indicate that peptide mimics of carbohydrates provide a novel strategy for the further development of reagents that elicit immune responses to carbohydrate epitopes associated with many infectious organisms and tumor cells.
\end{abstract}

Keywords: applied immunology, peptide mimetic, carbohydrate, polysaccharide, HIV-1, Lewis Y

Protein-carbohydrate interactions mediate the initial steps in many bacterial and viral infections. The envelope (env) glycoprotein of human immunodeficiency viruses (HIV-1 and HIV-2) interacts with target cells through high mannose and/or N- and O-glycosylated regions of gp160 (ref. 1). Subsequently, certain lectins and anticarbohydrate antibodies display the capacity to neutralize HIV field and laboratory isolates in vitro ${ }^{2-6}$. $\mathrm{O}$ - and $\mathrm{N}$-linked carbohydrates are one set of common saccharide subunits shared among bacteria, viruses, and tumor cells. Antibodies that target the Tn (GalNAc-Ser/Thr), sialo-syl-Tn (NeuAc-GalNAc-Ser/Thr), and the Histo-blood group antigen Lewis $Y$, (Fuc $\alpha 1 \rightarrow 2$ Gal $\beta 1 \rightarrow 4$ (Fuc $\alpha 1 \rightarrow 3$ ) GlcNAc $\beta 1 \rightarrow 3 \mathrm{Gal} \beta 1 \rightarrow 4 \mathrm{Glc} \beta 1 \rightarrow \mathrm{R})$, occurring as surface antigens on most primary human breast carcinomas and their metastases, inhibit HIV infection and syncytium formation ${ }^{5}$. These observed cross-reactivities for HIV and tumor cell-associated carbohydrates suggest that the pathophysiology of infection and neoplasia are profoundly affected by the same or similar carbohydrate forms.

Viral-borne carbohydrates that are not structurally encoded by the viral genome represent a target for group-specific vaccine development as these antigens are unlikely to change dramatically with viral mutation. Unfortunately, carbohydrates are, per se, not immunogenic in humans and require extrinsic adjuvanticity, as they suffer from an inherent inability to generate antigen-specific $\mathrm{T}$ cell responses. Immune responses can be enhanced by coupling carbohydrates to immunologic-carrier proteins or administering them with adjuvants ${ }^{7}$; however, synthetic antigen-conjugates (representative of those on the HIV-1 env) do not always induce immune responses reactive with native antigens ${ }^{8,9}$.

To overcome this and related deficiencies, surrogate peptide antigens might prove effective for eliciting immune responses reactive with natural carbohydrate forms ${ }^{10}$. In this context peptide mimetics have a significant conceptual advantage for vaccine design. As peptides, they have the ability to stimulate $\mathrm{T}$ cell help in an antigen specific manner. Ultimately, such a vaccine should be able to generate long-term immune responses, and would have advantages for manufacturing and vaccine production. The ability of a peptide or polypeptide to immunologically mimic a carbohydrate determinant $t^{11-15}$ indicates that while mimicry is accomplished using amino acids in place of sugars, the specificity pattern can be precisely reproduced.

We show that immunization with peptides that mimic mannose and lactoseries carbohydrate subunits induce antibodies that cross-react with native HIV env proteins and can neutralize HIV-1 infection. These studies substantiate that induced antibodies to common carbohydrate subunits found on bacteria and tumor cells can also bind viral glycoprotein(s). Peptide antigens that are mimics of carbohydrate antigens thus provide an alternative vaccine strategy to elicit an appropriate immune response against natural polysaccharides.

\section{Results}

Choice of peptides. Peptides were chosen based upon the distribution of mucin-type and peripheral poly- $\mathrm{N}$-acetylglucosamine carbohydrates on the major env protein of HIV-1 (refs. 4, 5, 16). Peptide motifs identified to mimic these carbohydrate forms are 


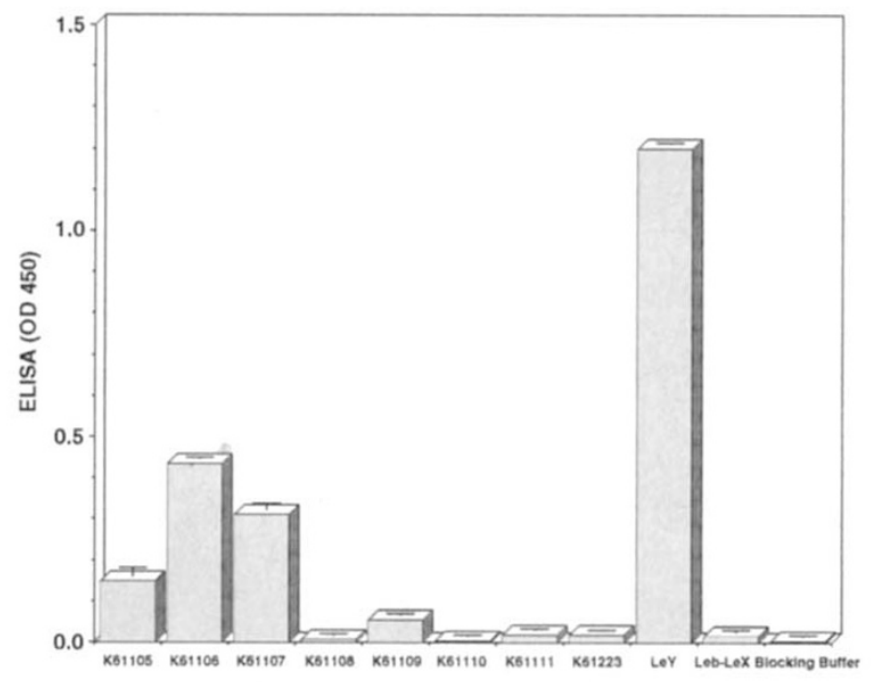

Peptides or Carbohydrates

Figure 1. Binding of the LeY specific antibody BR55-2 to various peptides and LeY. The peptides K61105, K61106, and K61107 correspond to YYPYD, YYRYD, and YWRYD respectively. Other $K$ series peptides were variants of the motifs or irrelevant peptides. Blocking buffer alone was also used as a control because anticarbohydrate antibodies have a tendency to adsorb to blocking agents, enhancing nonspecific binding.
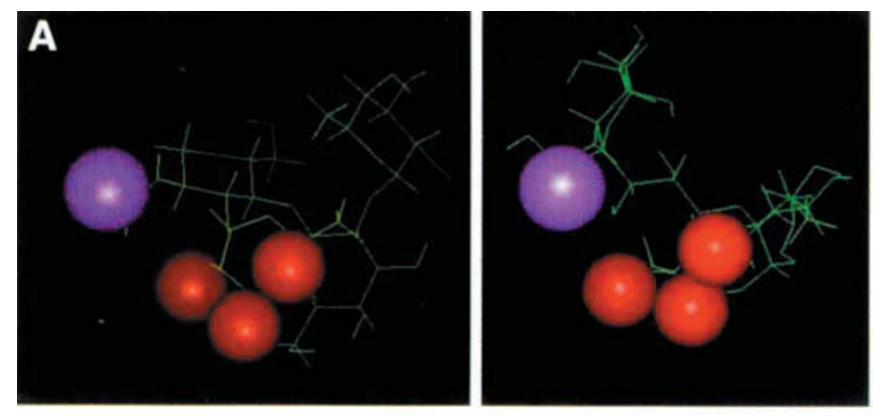

B

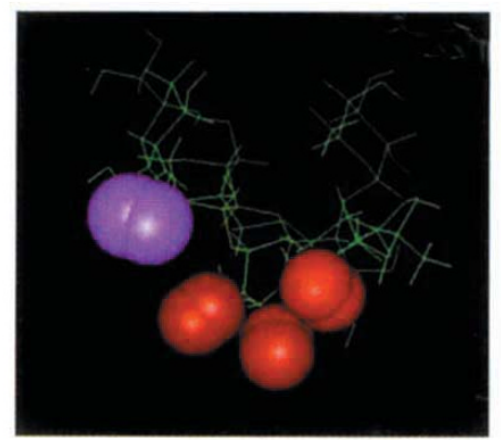

Figure. 2 Functional group similarities between LeY and MCP. (A) Lowenergy conformers of LeY (on left side of panel A) and MCP (on right side of panel A) are compared highlighting the conserved spatial positions of the methyl group on GlcNAc (magenta colored sphere) and hydroxyl oxygens on the Fuc residue of Fuc1-3GlcNAc (red colored spheres) of the LeY structure and the methyl group of $\alpha 2$ sialic residue (magenta colored sphere) and hydroxyl oxygens (red colored spheres) of $\alpha 9$ MCP. (B) Superposition of LeY tetrasaccharide and MCP. In this orientation, the hydroxyl groups on the Fuc residue of Fuc1-3GIcNAc are spatially conserved with those of the $\alpha 9$ sialic residue of MCP, while the respective methyl groups on GICNAC and on $\alpha 2$ sialic residue are spatially conserved.

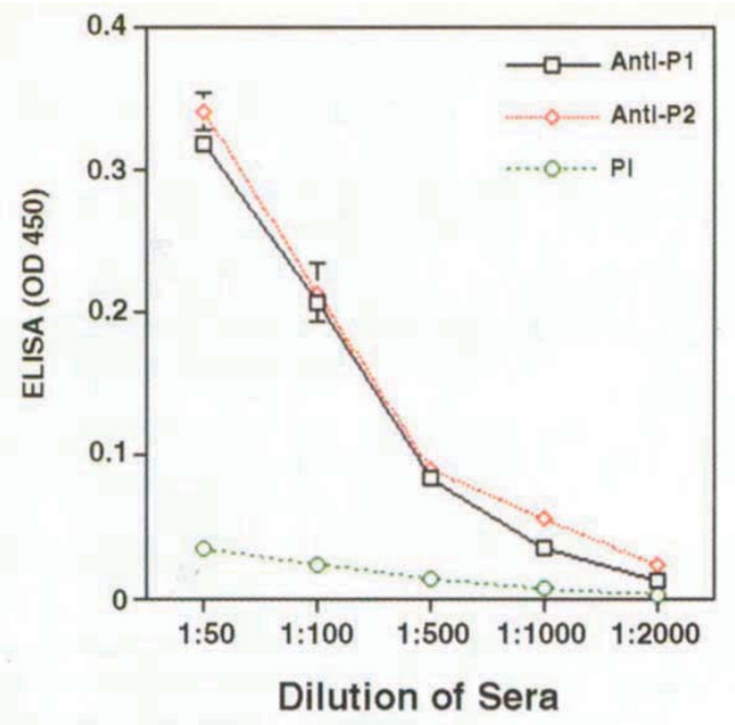

Figure 3 Binding of polyclonal antisera to LeY.

YPY, which has been found to mimic mannose ${ }^{17,18}$; WRY, which has been found to mimic $\alpha(1-4)$ glucose ${ }^{19,20}$; PWLY, found to mimic $\mathrm{LeY}^{21}$; and YRY, found to mimic the major C polysaccharide $\alpha(2-9)$ sialic acid (MCP) of Neisseria meningitidis ${ }^{10}$. It is noteworthy that these potential surrogate immunogens involve aromatic-aromatic interactions, suggesting that the motifs mimic carbohydrate subunits shared among a variety of carbohydrate forms.

The antigenic mimicry of LeY by the planar-X-planar motifs is shown in Figure 1. ELISA reactivities of YPY, YRY, and WRY motifs with the anti-LeY monoclonal antibody BR55-2 indicate that BR55-2 is specific for these motifs, displaying very little reactivity with other peptide sequences. BR55-2 displays high specificity for LeY, being made against an LeY-expressing tumor cell line ${ }^{22}$. We have recently determined the molecular recognition properties of LeY for BR55-2 (ref. 23), and that the LeY tetrasaccharide core structure is similar to the core structure of MCP (Fig. 2). The low energy-conformations of MCP and LeY structures overlap in their antigenic presentation, which may be mimicked by homologous peptides (Fig. 1).

Anti-LeY response to peptides. To determine the extent to which aromatic-aromatic motifs immunologically mimic the LeY antigen, we immunized Balb/c and $\mathrm{C} 57 \mathrm{Bl} / 6$ mice with peptides containing YYPYD (P1) and YYRYD (P2) motifs. We also immunized with a peptide that changes the YYRYD sequence tract to YYRGD (P3). The RYD sequence has been shown to be a mimic for the adhesion motif RGD and its conformational

Table 1. Mean florescence of binding of antipeptide sera to different cells as measured by FACS.

\begin{tabular}{lccc}
\hline Cell line & Anti-P1 (YYPY) & Anti-P2 (YYRYD) & Anti-P3 (YYRGD) \\
\hline SKBR3 & 240.6 & 275.6 & 166.7 \\
HS578 Bst & & & \\
(normal breast) & 17.8 & 19.9 & 22.4 \\
WM793 & 145.5 & 172.4 & 42.3 \\
MT2 & 19.5 & 22.3 & 23.1 \\
\hline
\end{tabular}

Background fluorescence (mean fluorescence) associated with nonspecific mouse sera is 24.2 for SKBR3, 24.4 for WM793, 17.3 for MT2, and 18.4 for HS578 (final sera concentration: 1:50). 
A

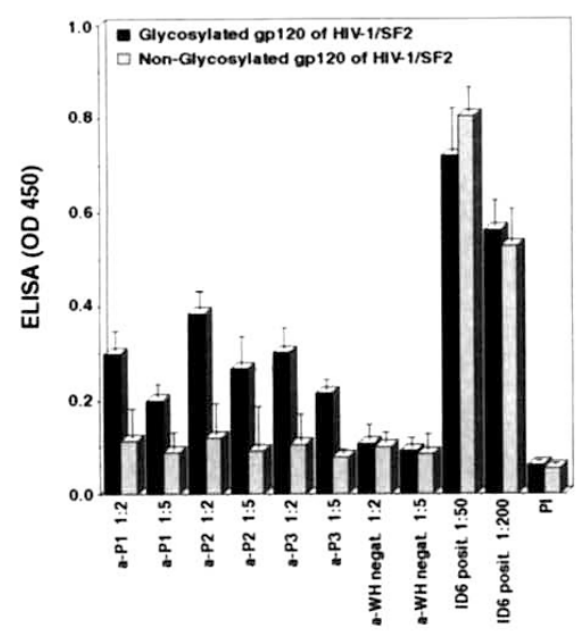

B

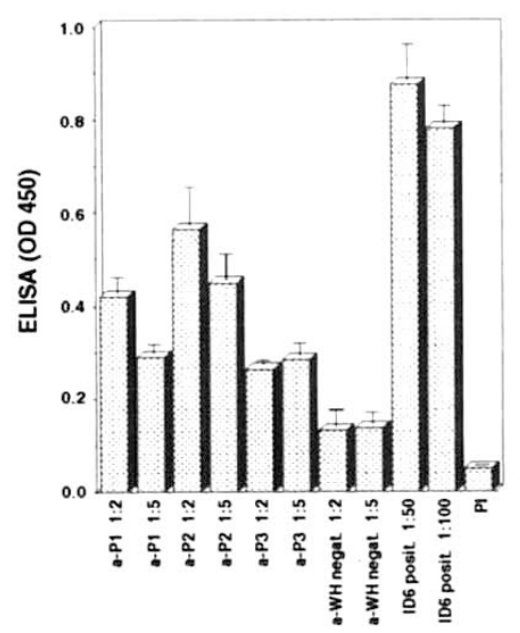

C

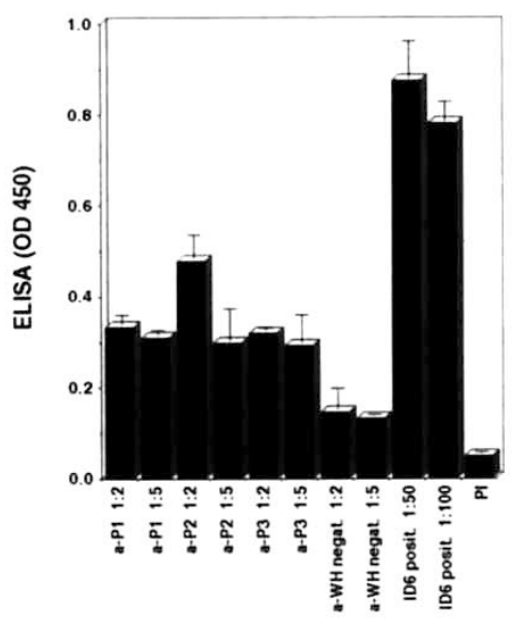

Figure 4. Binding of polycional antipeptide sera to HIV-1/SF2 and MN env protein. (A and B) Binding of sera derived from C57BI/6 immunized mice; (C) Binding of sera derived from Balb/c mice. PI in (A and B) is preimmune C57BI/6 sera. PI in (C) is preimmune Balb/c sera.

A

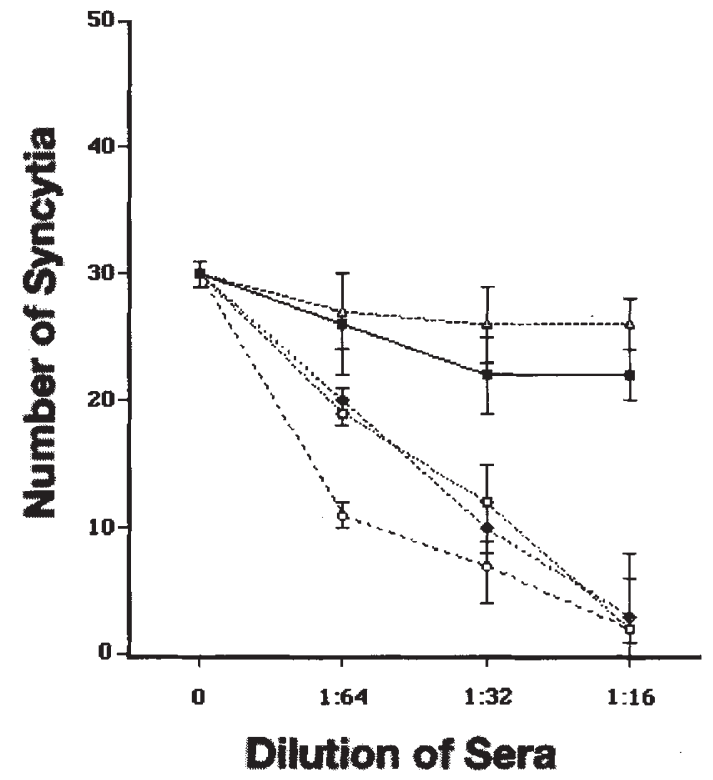

B

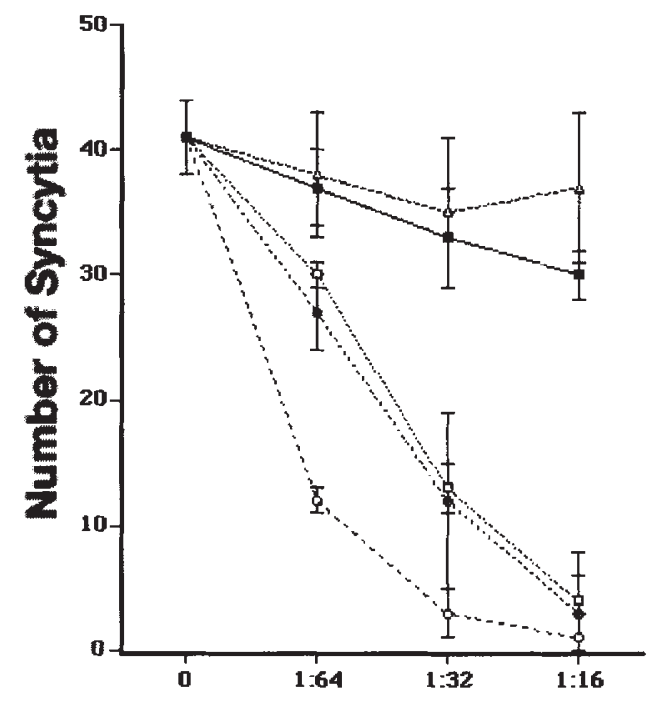

Dilution of Sera

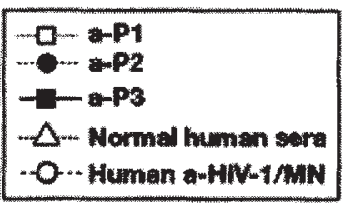

Figure 5. Inhibition of targetcell infection by cell-free HIV-1/MN. (A) Neutralization of MN by antipeptide sera derived in Balb/c mice; (B) Neutralization of MN by antipeptide sera derived in C57BL/6 mice. properties correlate with bioactive RGD compounds ${ }^{24}$. Peptides had the form CARIYYXYDGFAY, which followed the structural properties of an antibody loop ${ }^{10}$ or were synthesized as triple repeating units that emulate helical configurations, often observed for polysaccharides. It was observed that the reactivity of the IgG antisera to $\mathrm{P} 1$ and P2 titers out to 1:2000 against the LeY structure on solid phase ELISA (Fig. 3 ) with little reactivity observed from preimmune (PI) sera.

Envelope protein binding. We examined whether the polyclonal antipeptide sera derived from $\mathrm{C} 57 \mathrm{Bl} / 6$ bound to glycosylated and nonglycosylated forms of HIV-1/SF2 (Fig. 4A). Negative-control groups included preimmune sera, a mouse polyclonal monospecific antisera directed to an irrelevant antigen ${ }^{25}$ and a positive-control Balb/c monoclonal antibody (ID6) directed to HIV-1 glycosylated and nonglycosylated gp120 (ref. 26). Unexpectedly, we found that reactivity with the glycoslyated forms of HIV-I env provided statistically significant O.D. readings only up to $1: 5$ dilution. Nevertheless, within this dilution range we observed that the sera bound approximately threefold better to the glycosylated form of SF2 over preimmune sera background, while binding to the nonglycosylated form was equivalent to that observed for the negative-control murine sera derived from immunization with an irrelevant antigen.

We also examined this sera for binding to glycosylated gp 140 env protein of HIV-1/MN, lacking the transmembrane domain of gp4l (Fig. 4B). The antisera against all three peptide motifs bound 


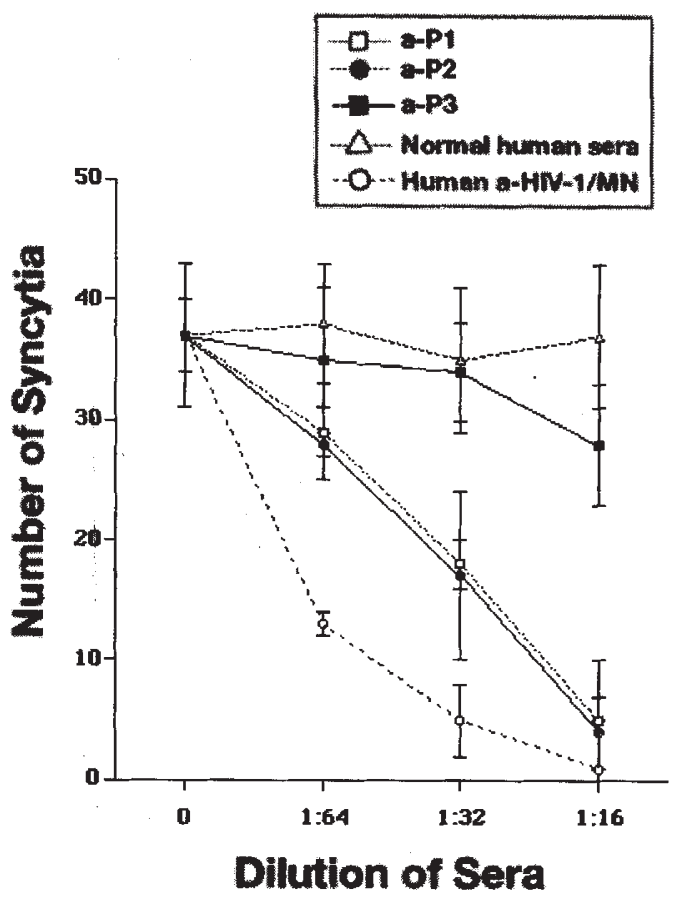

Figure 6. Inhibition of target cell infection by cell free HIV-1/3B isolate with sera derived from Balb/c mice.

to gp $140 \mathrm{HIV}-\mathrm{I} / \mathrm{MN}$ when used at final dilution of 1:5. Binding was at least twofold above the preimmune sera and sera derived from immunization with irrelevant antigen as background. The same result was observed with sera derived from $\mathrm{Balb} / \mathrm{c}$ animals (Fig. 4C). These results suggest that the antisera could recognize sugars on the HIV env protein, but perhaps the sugars were not presented in a proper orientation for maximum antisera reactivity to occur, or that the density of the carbohydrate expressed on the env protein surface was not high. In any event, our antisera bound to glycosylated but not to nonglycosylated gp120 derived from HIV-1 SF and MN.

Neutralization of HIV. Sera from Balb/c (Fig. 5A) and C57Bl/6 (Fig. 5B) mice immunized with $\mathrm{P} 1$ or $\mathrm{P} 2$, neutralized HIV-1/MN at final dilution's up to 1:64. Normal human sera and the anti-P3 sera were ineffective at blocking syncytia formation, whereas human $\alpha$-HIV-1 sera from four different infected patients neutralize cell-free virus at dilutions up to 1:64. The isolate specificity was further determined by cell-free neutralization of the HIV-1/3B isolate (Fig. 6). As with $\mathrm{MN}$, anti-P1 and anti-P2 Balb/c sera were effective in neutralizing virus infection in vitro. Collectively, these results suggest that the production of HIV-neutralizing antibodies by the peptide-proteosome complexes induces humoral immune responses in divergent haplotypes that can be as effective as sera from HIV-1-infected individuals in neutralizing HIV-1 cell-free infection.

Binding of immune sera to cells. To further confirm that the peptide-induced antisera were reacting with virus but not target cells used in the neutralization assay, we investigated binding of the sera to different cell lines including the MT-2 human $\mathrm{T}$ cell line by FACS. All three antisera did not bind to the MT-2 line at all (Table 1). Importantly, the antisera also did not bind to normal breast cells, HS578, which suggests that there is little to no tissue adsorption of the antipeptide sera in normal tissue. All three sera reacted very strongly with the LeY-expressing SKBR3 human breast-cancer line. Two out of three antisera also bound the human melanoma cell line WM793, which expresses sialyated GD2/GD3 gangliosides. While the antisera recognized overly expressed carbohydrate antigens on two control cell lines, no binding to the target MT-2 cells was observed, suggesting that the mechanism of inhibition of viral infection is connected with binding of the antipeptide sera to viral particles.

\section{Discussion}

Comparison of oligosaccharide profiles on the HIV env protein reveals that different virus isolates, propagated in the same host cells, yield very similar glycan patterns, whereas cultivation of an isolate in different host cells results in markedly divergent oligosaccharide maps ${ }^{27}$. Variations concern the proportion of highmannose-type, hybrid-type, and complex-type substituents, as well as the state of charge and structural parameters of the complextype species. As a characteristic feature, complex-type glycans of monocyte-derived-macrophage-derived viral glycoprotein are almost exclusively substituted by lactosamine repeats.

We and others have found that certain peptides mimic carbohydrate subunits, inducing cross-reactive in vivo anticarbohydratelike antibody responses. We have shown that aromatic containing peptide motifs can mimic salient features of at least one lactosamine form, LeY. Unlike synthetic carbohydrate forms $\mathrm{s}^{8,9}$, sera induced with these peptide motifs bound to an LeY-expressing cell line and can neutralize HIV-1 cell-free infection in vitro. The specificity in the neutralization profile is illustrated by considering that a change in one amino acid in an immunizing peptide (YYRYD to YYRGD) can affect the neutralizing ability of the antipeptide sera. We have found that the production of HIVneutralizing antibodies was not severely major histocompability complex-restricted, and cross-reacts and cross-neutralizes with at least two divergent isolates within clade B; the major North American and Western European clade. We do not know at this time if the antipeptide sera inhibit primary isolates of HIV-1, which are more resistant to neutralization ${ }^{27-30}$.

It was not the intent of these studies to advocate a new vaccine that displays broad HIV-1 neutralization ability, but rather to draw attention to the possibility of developing peptides that mimic HIV-1-associated carbohydrate forms. We found that aromatic-aromatic interactions are a major driving force in mimicking carbohydrate subunits. Polymerization of aromatic residue-containing peptides can structurally mimic the helical shape of many carbohydrate forms. While carbohydrate-conjugate vaccines are certainly effective and are viewed as superior to peptide mimics, peptide mimics might be used as priming or boosting agents, being formulated to develop longer-lasting responses after booster immunization. As peptides have the ability to stimulate $\mathrm{T}$ cell help in an antigen-specific manner, peptide mimetics would be of importance as novel agents for adjuvant therapy. Peptides that mimic carbohydrates may be further designed and manipulated to develop specific immune responses against a variety of polysaccharides on bacteria, viruses, and tumors that might be associated with their pathobiology.

\section{Experimental protocol}

Generation of polyclonal sera. Peptides were synthesized with the addition of a tripeptide YGG spacer, and a cysteine at the amino terminus conjugated to a lauroyl group (Bio-Synthesis, Lewisville, TX) and then complexed with proteosomes ${ }^{10}$. For generation of polyclonal sera, Balb/c mice $\left(\mathrm{H}-2^{\mathrm{d}}\right)$ (four per group) and $\mathrm{C} 57 \mathrm{Bl} / 6\left(\mathrm{H}-2^{\mathrm{b}}\right)$ (four per group) 4 to 6 weeks of age, were immunized intraperitoneally on a weekly basis for 3 weeks with $50 \mu \mathrm{g}$ of peptide-proteosome complex. Sera were collected within 7 to 14 days after the last immunization and analyzed for binding against LeY by ELISA .

Binding of immune sera and BR55-2 to LeY and peptides. Solid-phase ELISA was performed to asses the binding activity of the generated sera to LeY incorporated into polyacrylamide (PAA) matrix, creating $30 \mathrm{kDa}$ multivalent polymer (GlycoTech Inc., Rockville, MD). Immunlon 2 plates were 
coated with the multivalent LeY-PAA probe overnight at $4^{\circ} \mathrm{C}$. The plates were blocked with $0.5 \% \mathrm{FCS} / 0.2 \%$ tween , $200 \mu \mathrm{l} /$ well, $37^{\circ} \mathrm{C}$, for $1 \mathrm{~h}$. Serial dilutions of the respective antisera were added and incubated at $37^{\circ} \mathrm{C}$ for $2 \mathrm{~h}$ and resolved with $100 \mu \mathrm{l} /$ well of 1:10,000x goat antimouse IgG isotype matched HRP (Sigma, St. Louis, MO) diluted in blocking buffer, incubated at $37^{\circ} \mathrm{C}$ for $1 \mathrm{~h}$, and read at $\mathrm{OD}_{450}$. This same protocol was used in assessing BR55-2 binding to various peptides and carbohydrate probes. Peptides were presented as MAP peptides (Genetics Research, Huntsville, AL) coated at $2 \mu \mathrm{g} /$ well. Multivalent LeY and Leb-LeX probes were coated at $0.1 \mu \mathrm{g} / \mathrm{well}$ and the monoclonal antibody BR55-2 (IgG3) concentration used was $0.1 \mu \mathrm{g}$.

Binding of immune sera to cells. Cells, with FACS buffer ( $1 \% \mathrm{BSA}$, $0.01 \% \mathrm{Na}$ azide, $25 \mathrm{mM}$ EDTA) were washed, scraped and transferred to $15-\mathrm{ml}$ centrifuge tubes. Viability of cells was checked by trypan blue and $100 \mu$ of 1 to $2 \times 10^{6} / \mathrm{ml}$ cells in FACs buffer were used for analysis. Ten microliters of experimental or control sera were added to sample tubes and incubated on ice for $30 \mathrm{~min}$, washed twice and $10 \mu \mathrm{l}$ of FITC Ab (goat antimouse IgG conjugate FITC-labeled (Sigma) diluted 1:20 with PBS) was added to the sample. Cells were fixed with $1 \%$ paraformaldelhyde, followed by FACS measurement.

Binding of immune sera to HIV envelope protein. Oligomeric soluble gp140, a truncated env of the HIV-1/MN, was produced by BS-C- 1 cells infected with VPE12B, recombinant vaccinia virus, and was purified ${ }^{31}$. Bacteria produced nonglycosylated SF2 gp120 and Chinese hamster ovary cells produced glycosylated SF2 gp120 were obtained from the AIDS Research and Reference Reagent Program (Rockville, MD). Binding of sera were determined by ELISA as previously described ${ }^{26}$. Briefly, $2 \mu \mathrm{g} / \mathrm{ml}$ of recombinant proteins were adsorbed onto microtiter wells. Serial dilutions of experimental or control antisera were added to these antigen-coated plates. Wells were washed, incubated with goat antimouse IgG conjugated with HRPO (Sigma), and developed with 3,3',5,5'-tetramethylbenzidine dihydrochloride (TMB).

Viral neutralization assay. Cell-free HIV-1/MN and HIV-I/3B, obtained from the AIDS Research and Reference Reagent Program, were propagated in $\mathrm{H} 9$ cells. Cell-free virus neutralization was performed as previously described ${ }^{32,33}$ with minor modifications. One hundred TCID $_{50}$ of HIV-1/MN or HIV-1/3B cell-free virus $(50 \mu \mathrm{l})$ were preincubated with serial dilutions of experimental antisera or controls (preimmune mouse sera, normal human sera, or mixture of four sera of HIV-1 positive patients) for $1 \mathrm{~h}$ at $37^{\circ} \mathrm{C}$. Following incubation, the pretreated virus was then plated on $4 \times 10^{4} \mathrm{HTLV}$ I/MT-2 target cells $(50 \mu \mathrm{l})$, for $1 \mathrm{~h}$ at $37^{\circ} \mathrm{C}$. The target cells were then washed three times and incubated at $37^{\circ} \mathrm{C}$ with $5 \% \mathrm{CO}_{2}$. Neutralization was detected as inhibition of syncytia 3 days later, assessed by counting the number of multinuclear cells ${ }^{33}$.

\section{Acknowledgments}

We graciously thank Bin Wang for recombinant glycosylated gp 140. This work was funded by the USAMRMC (DAMD17-94-J-4310) Breast Cancer Initiative (TKE). DBW was supported in part by a SPIRAT grant from NIH.

1. Robinson, W.J. Montefiori, D.C., and Mitchell, W.M. 1987. Evidence that mannosyl residues are involved in human immunodeficiency virus type 1 (HIV-1) pathogenesis. AIDS Res. Hum. Retroviruses 3:265-282.

2. Bolmstedt, A., Olofsson, S., Sjogren, J.E., Jeansson, S., Sjoblom, I. Akerblom, L., et al. 1992. Carbohydrate determinant NeuAc-Gal beta (1-4) of $\mathrm{N}$-linked glycans modulates the antigenic activity of human immunodeficiency virus type 1 glycoprotein gp120. J. Gen. Virol. 73:3099-3105.

3. Gattegno, L., Ramdani, A., Jouault, T., Saffar, L., and Gluckman, J.C. 1992 Lectin-carbohydrate interactions and infectivity of human immunodeficiency virus type 1 (HIV-1). AIDS Res. Hum. Retroviruses 8:27-37.

4. Muller, W.E., Bachmann, M. Weiler, B.E. Schroder H.C., Uhlenbruck, G. Shinoda, T., et al. 1991. Antibodies against defined carbohydrate structures of Candida albicans protect $\mathrm{H} 9$ cells against infection with human immunodeficiency virus-1 in vitro. J. Acquired Immune Deficiency Syndromes 4:694-703.

5. Hansen, J.E., Nielsen, $C_{\text {.i }}$ Arendrup, M., Olofsson, S., Mathiesen, L., Nielsen, J.O. et al. 1991. Broadly neutralizing antibodies targeted to mucin-type carbohydrate epitopes of human immunodeficiency virus. J. Virol. 65:6461-6467.

6. Furukawa, K., Akagi, T., Nagata, Y., Yamada, Y., Shimotohno, K., Cheung, N.K., et al. 1993. GD2 ganglioside on human T-lymphotropic virus type Iinfected $T$ cells: possible activation of beta-1,4-N-acetylgalactosaminyltransferase gene by p40tax. Proc. Natl. Acad. Sci. USA 90:1972-1976.

7. Mond, J.J., Lees, A., and Snapper, C.M. 1995. T cell-independent antigens type 2. Annu. Rev. Immunol. 13:655-692.

8. Kitamura, K., Stockert, E., Garin, C.P., Welt, S., Lloyd, K.O., Armour, K.L., et al. 1994. Specificity analysis of blood group Lewis-y (Le(y)) antibodies generated against synthetic and natural Le(y) determinants. Proc. Natl. Acad.
Sci. USA 91:12957-12961.

9. Adluri, S., Helling, F., Ogata, S., Zhang, S., Itzkowitz, S.H., Lloyd, K.O., et al 1995. Immunogenicity of synthetic TF-KLH (keyhole limpet hemocyanin) and sTn-KLH conjugates in colorectal carcinoma patients. Cancer Immunol. Immunother. 41:185-192.

10. Westerink, M.A.J., Giardina, P.C., Apicella, M.A., and Kieber-Emmons, T. 1995. Peptide mimicry of the meningococcal group $C$ capsular polysaccharide. Proc. Natl. Acad. Sci. USA 92:4021-4025.

11. Sugiyama, T., Imai, K., Ono, A., Takayama, Y., Tsujisaki, M., Taki, T., et al 1991. Conformational structure of a monocional anti-idiotypic antibody to the monoclonal anti-adenocarcinoma-associated carbohydrate antibody YH206. J. Immunol. 146:3097-1301.

12. Diakun, K.R. and Matta, K.L. 1989. Synthetic antigens as immunogens: part III. Specificity anaiysis of an anti-anti-idiotypic antibody to a carbohydrate tumor-associated antigen. J. Immunol. 142:2037-2040.

13. Shikhman, A.R. and Cunningham, M.W. 1994. Immunological mimicry between $\mathrm{N}$-acetyl-beta-D-glucosamine and cytokeratin peptides. Evidence for a microbially driven anti-keratin antibody response. $J$. Immunot. 152:4375-4387.

14. Tsuyuoka, K., Yago, K., Hirashima, K., Ando, S., Hanai, N., Saito, H., et al. 1996. Characterization of a $\mathrm{T}$ cell line specific to an anti-Id antibody related to the carbohydrate antigen, sialyl SSEA-1, and the immundominant $T$ cell antigenic site of the antibody. J. Immunol. 157:661-669.

15. Hutchins, W., Adkins, A., Kleber-Emmons, T., and Westerink, M.A.J. 1996 Molecular characterization of a monoclonal antibody produced in response to a group-C Meningococcal polysaccharide peptide mimic. Mol. Immunol. 33:503-510

16. Imberty, A. and Perez, S. 1994. Molecular modelling of protein-carbohydrate interactions. Understanding the specificities of two legume lectins towards oligosaccharides. Glycobiology 4:351-366.

17. Oldenburg, K.R., Loganathan, D., Goldstein, I.J., Schultz, P.G., and Gailop M.A. 1992. Peptide ligands for a sugar-binding protein isolated from a random peptide library. Proc. Natl. Acad. Sci. USA 89:5393-5397.

18. Scott, J.K., Loganathan, D., Easley, R.B., Gong, X., and Goldstein, I.J. 1992 A family of concanavalin A-binding peptides from a hexapeptide epitope library. Proc. Natl. Acad. Sci. USA 89:5398-5402.

19. Murai, H., Hara, S., Ikenaka, T., Goto, A., Arai, M., and Murao, S. 1985 Amino acid sequence of protein alpha-amylase inhibitor from Streptomyces griseosporeus YM-25. J. Biochem. 97:1129-1133.

20. Mirkov, T.E., Evans, S.V., Wahistrom, J., Gomez, L., Young, N.M., and Chrispeels, M.J. 1995. Location of the active site of the bean alpha-amylase inhibitor and involvement of a Trp, Arg, Tyr triad. Glycobiology 5:45-50.

21. Hoess, R., Brinkmann, U., Handel, T., and Pastan, I. 1993. Identification of a peptide which binds to the carbohydrate-specific monoclonal antibody B3. Gene 128:43-49.

22. Steplewski, Z., Blaszczyk, T.M., Lubeck, M., Loibner, H., Scholz, D., and Koprowski, H. 1990. Oligosaccharide $Y$ specific monoclonal antibody and its isotype switch variants. Hybridoma 9:201-210.

23. Thurin-Blaszczyk, M., Murali, R., Westerink, M.A.J., Steplewski, Z., Co, M S., and Kieber-Emmons, T. 1996. Molecular recognition of the Lewis $Y$ antigen by monoclonal antibodies. Protein Eng. 9:101-113.

24. Prammer, K.V., Boyer, J., Ugen, K., Shattil, S.J., and Kieber-Emmons, T. 1994. Bioactive Arg-Gly-Asp conformations in anti-integrin GPiib-iiia antibodies. Receptor 4:93-108.

25. Agadjanyan, M.G., Ugen, K.E., Wang, B., Williams, W.V., and Weiner, D.B. 1994. Identification of an 80-kilodalton membrane glycoprotein important for human T-cell leukemia virus type $I$ and type II syncytium formation and infec tion. J. Virol. 68:485-493

26. Ugen, K.E., Rafaell, Y. Fiegner, U., Agadjanyan, M.G., Satre, M., Srikantan, V., et al. 1993. Generation of monoclonal antibodies against the amino region of GP120 which elicits antibody dependent cellular cytotoxicity. Modern approaches to new vaccines including prevention of AIDS. pp. 215-221 in Vaccines. Cold Spring Harbor Press, Cold Spring Harbor, NY.

27. Willey, R.L., Shibata, R., Freed, E.O., Cho, M.W., and Martin, M.A. 1996 Differential glycosylation, virion incorporation, and sensitivity to neutralizing antibodies of human immunodeficiency virus type 1 envelope produced from infected primary T-lymphocyte and macrophage cultures. J. Virol 70:6431-6436.

28. Trkola, A:, Purtscher, M., Muster, T., Ballaun, C., Buchacher, A., Sullivan, N., et al. 1996. Human monoclonal antibody $2 \mathrm{G} 12$ defines a distinctive neutralization epitope on the gp120 glycoprotein of human immunodeficiency virus type 1. J. Virol. 70:1100-1108.

29. Moore, J.P., Cao, Y., Qing, L., Sattentau, Q.J., Pyati, J., Koduri, R., et al. 1995. Primary isolates of human immunodeficiency virus type 1 are relatively resistant to neutralization by monoclonal antibodies to gp 120 , and their neutralization is not predicted by studies with monomeric gp120. J. Virol. 69:101-109.

30. Gram, G.J., Hemming, A., Bolmstedt, A., Jansson, B., Olofsson, S. Akerblom, L., et al. 1994. Identification of an N-linked glycan in the V1-loop of HIV-1 gp120 influencing neutralization by anti-V3 antibodies and soluble CD4. Arch. Virol. 139:253-261.

31. Earl, P.L., Broder, C.C., Long, D., Lee, S.A., Peterson, J., Chakrabarti, S., et al. 1994. Native oligomeric human immunodeficiency virus type 1 envelope glycoprotein elicits diverse monoclonal antibody reactivities. J. Virol. 68:3015-3026.

32. Montefiori, D.C., Robinson, W.J., Schuffman, S.S., and Mitchell, W.M. 1988 Evaluation of antiviral drugs and neutralizing antibodies to human immunodeficiency virus by a rapid and sensitive microtiter infection assay. J. Clin Microbiol. 26:231-235.

33. Nara, P.L. and Fischinger, P.J. 1988. Quantitative infectivity assay for HIV-1 and -2 . Nature 332:469-470. 